\title{
Optimizing the parameters of amoxicillin removal in a photocatalysis/ozonation process using Box-Behnken response surface methodology
}

\author{
Elham Norabadi ${ }^{\mathrm{a}}$, Ayat Hossein Panahi ${ }^{\mathrm{b}}$, Reza Ghanbari ${ }^{\mathrm{c}, \mathrm{d}}$, Ali Meshkinian ${ }^{\mathrm{e}}$ \\ Hossein Kamani ${ }^{\mathrm{e}, *}$, Seyed Davoud Ashrafi ${ }^{\mathrm{f}, *}$
}

${ }^{a}$ Student Research Committee, Zahedan University of Medical Sciences, Zahedan, Iran, email: e.noorabadi17@gmail.com (E. Norabadi) ${ }^{b}$ Social Determinants of Health Research Center, Birjand University of Medical Sciences, Birjand, Iran, email: ayatpanahi@yahoo.com (A. Hossein Panahi)

'Social Determinants of Health Research Center, Qazvin University of Medical Sciences, Qazvin, Iran

${ }^{d}$ Department of Environmental Health Engineering, School of Health, Qazvin University of Medical Sciences, Qazvin, Iran

${ }^{e}$ Health Promotion Research Center, Zahedan University of Medical Sciences, Zahedan, Iran, Tel. +989155412919; Fax: +985433295837; emails: hossein_kamani@yahoo.com(H. Kamani),meshkinian@hotmail.com (A. Meshkinian)

${ }^{f}$ Department of Environmental Health Engineering, Research Center of Health and Environment, School of Health,

Guilan University of Medical Sciences, Rasht, Iran

Received 25 August 2019; Accepted 21 February 2020

\section{A B S T R A C T}

Concerns about environmental pollution from antibiotics such as amoxicillin have received increasing attention. These compounds should be eliminated from discharged effluents to avoid their possible negative effects on humans and animals, as well as on the environment. Recently, advanced oxidation techniques have been used to remove antibiotics. This work aims to study the removal of amoxicillin using a photocatalysis/ozonation process for treating pharmaceutical wastewater loaded with this type of refractory pollutants. The removal process was carried out using different $\mathrm{pH}$ values (3-11), catalyst dosages $(250-750 \mathrm{mg} / \mathrm{L})$, and reaction times (30-90 min), at an ozonation rate of $200 \mathrm{mg} / \mathrm{h}$. Statistical analysis indicated that a quadratic model was suitable for modeling amoxicillin degradation by the photocatalytic process and that all studied parameters had statistically significant critical levels. Under optimum conditions $(\mathrm{pH} 11$, a catalyst dose of $500 \mathrm{mg} / \mathrm{L}$, and a reaction time of $90 \mathrm{~min}$ ), the amoxicillin degradation efficiency of the photocatalytic process was $78.7 \%$. The results of the photocatalysis/ozonation process indicated that after 90 min of ozone injection, an amoxicillin degradation efficiency of $98.7 \%$ was obtained. Therefore, it was concluded that the combined ozonation process and photocatalytic process could be used to remove amoxicillin effectively.

Keywords: Amoxicillin; Photocatalysis/ozonation reaction; Optimization; Box-Behnken; RSM

\footnotetext{
${ }^{*}$ Corresponding authors.
} 